\title{
Thiosemicarbazide derivative-functionalized carbon nanotube for simultaneous determination of isoprenaline and piroxicam
}

\author{
Mohammad Mazloum-Ardakani", Hamideh Mohammadian-Sarcheshmeh, Alireza Khoshroo \\ and Mohammad Abdollahi-Alibeik
}

\begin{abstract}
Background: Piroxicam (PX) is a nonsteroidal anti-inflammatory drug of the oxicam category that has been known worth as a chemopreventative, anti-tumor agent, for acute and chronic musculoskeletal. To the best of our knowledge, no paper has been published until now reporting the simultaneous electrocatalytic detection of isoprenaline and PX by using any type of modified electrodes.

Methods: The glassy carbon electrode modified with multiwalled carbon nanotubes chemically modified with (z)-1(3,4-dihydroxybenzylidene)-2-methylthiosemicarbazide (DBT-CNT/GCE). The electrocatalytic behavior of analytes was examined using cyclic voltammetry (CV), chronoamperometry, and differential pulse voltammetry (DPV) on the modified electrode.

Results: In order to determine kinetic parameters such as the anodic transfer coefficient $(a=0.47)$ and the electron transfer rate constant between the nanocomposite and glassy carbon electrode $(\mathrm{ks} / \mathrm{s}=0.51)$, cyclic voltammetry was applied. The results represented a linear relationship versus isoprenaline concentrations in the wide range of 0 . 5-1500.0 $\mu \mathrm{M}$ and a detection limit of $0.35 \mu \mathrm{M}$. Furthermore, DPV was applied successfully for the simultaneous determination of isoprenaline and piroxicam.

Conclusions: This proposed sensor has been successfully applied to determine the IP and PX in blood serum human, which demonstrates that it has excellent potential application for detection of different concentrations of IP and PX.
\end{abstract}

Keywords: Isoprenaline, Piroxicam, Functionalized carbon nanotube, Thiosemicarbazide

\section{Background}

Carbon nanotubes have gotten a great deal of attention in all around the world due to their prominent mechanical, structural, and electronic properties. The newly developed chemical methods for chemical functionalization of carbon nanotubes, specially modification techniques, permit variation of the electronic properties of the tubes, as well as chemical surface properties. These functionalized carbon nanotubes have provided an extensive range of new applications such as nanostructured electronic devices, chemical

\footnotetext{
* Correspondence: mazloum@Yazd.ac.ir

Department of Chemistry, Faculty of Science, Yazd University, Yazd 89195-741, Iran
}

sensors, and electrochemical sensors (Balasubramanian and Burghard 2005; Mazloum-Ardakani et al. 2014; Mazloum-Ardakani et al. 2013). In addition, functionalized carbon nanotubes were used in the construction of polymeric carbon nanocomposites, the combination with biological species, and the probing of nanotube molecule interactions (Sun et al. 2002).

It is important to know that carbon nanotubes (CNTs) usually are agglomerates of several hundred micrometers in size (Wang et al. 2003). These entanglements cause nanotubes to disperse in polymer matrix difficultly. Therefore, it is essential that alter the chemical nature of the nanotube surface. Solution processing has been 
performed in the construction of the well-dispersed carbon nanotube composites. Nevertheless, it is difficult to attain homogeneous dispersion of nanotubes in polymer matrix, owing to the fact that carbon nanotubes are bundled and insoluble. Chemical functionalization of the CNT surface raises interfacial interaction between CNTs and the polymer matrix, increases adhesion of them in different polymers and organic solvents, decreases agglomeration, and improves dispersion (Andrews and Weisenberger 2004). The enhanced interactions between CNTs and the polymer matrix improve the load transfer from the polymer to the nanotubes. Acid treatment of the nanotube is an important technique to chemical functionalization. It produces functional groups on sidewalls or open ends of nanotubes, removes catalytic impurities, and simplifies dispersion of CNTs in various solutions or melts. Also, the amine treatment and heat treatment are usually used for chemical functionalization of carbon nanotubes (Lee et al. 2007).

Researchers have used another type of classification for functionalization methods. These are various covalent and noncovalent functionalization methods for chemical modification and solubilization of single-walled (SWNT) and multiwalled (MWNT) carbon nanotubes (Bahr and Tour 2001; Chen et al. 2001a; Georgakilas et al. 2002; Holzinger et al. 2001; Huang et al. 2003; Jin et al. 2000; Lin et al. 2002; Riggs et al. 2000; Sun et al. 2001; Tasis et al. 2006). Covalent functionalization approaches are coupling reactions that target oxidized defect sites on the carbon nanotube surface and additional reactions that perform for graphite surfaces conventionally. Covalent functionalization approaches can disorder the expanded $\Pi$-networks on the carbon nanotube surfaces and decrease both their electrical and mechanical properties. To solve these problems, noncovalent approaches were introduced. In comparison with covalent functionalization, noncovalent functionalization is an easier method and has the benefit of preserving nanotube's $\mathrm{sp}^{2}$ structure, therefore preserving the electronic properties (Fernando et al. 2004; Tournus et al. 2005). Noncovalent approaches use different types of functionalization agents involving polymers, poly nuclear aromatic compounds, surfactants, and biomolecules for the noncovalent dispersion of carbon nanotubes (Reddy et al. 2009). Among these approaches, modifying the nanotube surface using aromatic moieties is very significant (Chen et al. 2001b).

In this work, thiosemicarbazide derivative-functionalized multiwalled carbon nanotubes were used for modification of a glassy carbon electrode in order to determine isoprenaline (IP) and piroxicam (PX). Piroxicam or [4-hydroxy-2-methyl-N-(2-pyridyl)-H-1,2-benzothiazine-3-carbo xamide-1,1-di-oxide] is a nonsteroidal anti-inflammatory drug (NSAID) of the oxicam category that has been known worth as a chemopreventative, anti-tumor agent, for acute and chronic musculoskeletal and joint disorders such as ankylosing spondylitis, rheumatoid arthritis, and osteoarthritis (Kate et al. 2013).

Isoprenaline or isoproterenol (4-[1-hydroxy-2-[(1-methylethyl)amino]ethyl]-1,2-benzenediol) is a significant neurotransmitter applied to cure the neural disorders such as Parkinson's disease (Stryer 1990). IP is a catecholamine drug that is extremely utilized in the cure of allergic emergencies, bronchial asthma, status asthmatic, cardiac arrest, and ventricular bradycardia (Mandell and Petri 1996).

Here, electrochemical analysis was performed by a glassy carbon electrode with added multiwalled carbon nanotubes chemically modified with (z)-1-(3,4-dihydroxybenzylidene)2-methylthiosemicarbazide (DBT-CNT/GCE). Thiosemicarbazide derivative compound was selected as a modifier because this compound is insoluble in aqueous solution (Benvidi et al. 2011; Mazloum-Ardakani et al. 2010; Mazloum-Ardakani et al. 2009). Furthermore, this compound shows a redox behavior which can reduce overpotential oxidation of analytes and electrocatalytic effect (Jin and Lin 2004; Murray 1984; Zhu et al. 2007).

In comparison to bare electrodes, modified electrodes improve the motion of electrons between the analyte and electrodes, which causes a substantial reduction in activation potential (Beitollahi et al. 2008). In addition, these electrodes are less affected by surface fouling and oxide formation (Santana et al. 2009). In fact, electrode modification improves sensitivity, reproducibility, electron transfer reaction, stability, and high overpotential for the electron transfer process. To the best of our knowledge, no paper has been published until now reporting the simultaneous electrocatalytic detection of IP and PX by using any type of modified electrodes. The modified electrode (DBT-CNT/GCE) was used to investigate electrocatalytic behavior of isoprenaline in phosphate buffer solution ( $\mathrm{pH}=7.0)$ using cyclic voltammetry, chronoamperometry, and differential pulse voltammetry (DPV). Moreover, it was used to detect different concentrations of IP and PX in solution simultaneously. The calibration curve was plotted to obtain the linear concentration range and detection limit. To examine the applicability of the proposed electrode for real sample analysis, the recovery of IP, PX was determined. The results showed that the suggested electrode has been successfully employed for the evaluation of the above compounds in real samples.

\section{Methods}

\section{Apparatus and chemicals}

The electrochemical measurements were performed with a potentiostat/galvanostat (SAMA 500, electro analyzer system, I.R. Iran) at the ambient temperature. In all experiments were applied a three-electrode assembly including a saturated calomel as the reference electrode, 
a platinum wire as the counter electrode, and DBT$\mathrm{CNT} / \mathrm{GCE}$ as the working electrode. All potentials were quoted vs. reference electrode. A Metrohm 691 pH/ion meter was used to $\mathrm{pH}$ measurements. The solutions were freshly prepared with doubly distilled water. Buffer solution was prepared from orthophosphoric acid and its salts in the $\mathrm{pH}=7.0$. Multiwalled carbon nanotubes (MWCNT) is obtained from PlasmaChem GmbH company. The IP, PX, and other reagents were of analytical grade (Merck). Also, DBT and functionalized carbon nanotubes were synthesized in our laboratory.

\section{Synthesis of (z)-1-(3,4-dihydroxybenzylidene)-2- methylthiosemicarbazide}

In 10-mL round bottom flask, 3,4-dihydroxybenzaldehyde $(1 \mathrm{mmol})$, thiosemicarbazide $(1 \mathrm{mmol})$, and methanol $(5 \mathrm{~mL})$ were taken and refluxed at $65^{\circ} \mathrm{C}$ for $4 \mathrm{~h}$. The precipitated product was filtered and washed with methanol. Further, purification was performed with recrystallization of the solid product in ethanol. NMR data: ${ }^{1} \mathrm{H}$ NMR $\left(250 \mathrm{MHz}, \mathrm{DMSO}-d_{6}\right): \delta(\mathrm{ppm})=$ 9.63( $(\mathrm{OH}, 1 \mathrm{H}), \quad 9.07(\mathrm{OH}, 1 \mathrm{H}), \quad 8.08(\mathrm{CH}=\mathrm{N}, 1 \mathrm{H}, \mathrm{S})$, 7.81(NH, $1 \mathrm{H}), 7.20\left(\mathrm{NH}_{2}, 2 \mathrm{H}, \mathrm{S}\right), 7.09-6.78(\mathrm{Ar}, 3 \mathrm{H})$. FTIR data: FTIR (KBr disk), 3446, 3329, 3178, 1620, 1592, $1538,1508,1365,1279,979,867$, and $841 \mathrm{~cm}^{-1}$. Scheme 1 shows chemical structure of thiosemicarbazide derivative.

\section{Oxidation of CNTs}

We performed acid treatment method to oxidation of CNTs. The MWCNTs were immersed in a $65 \%$ solution of 3:1 mixture of $98 \% \mathrm{H}_{2} \mathrm{SO}_{4}$ and $68 \% \mathrm{HNO}_{3}$, and the suspension was heated at $100{ }^{\circ} \mathrm{C}$ for $30 \mathrm{~min}$. Then, they were washed several times with deionized water on a filter paper with the pore size of $1 \mathrm{~mm}$ and were dried in a vacuum oven at $90{ }^{\circ} \mathrm{C}$ for 1 day. In this process, MWCNTs were oxidized and purified by omitting impurities.

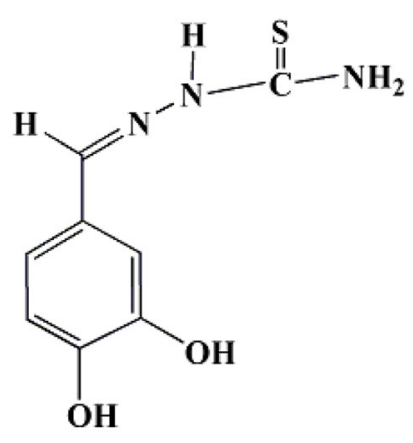

(Z)-1-(3,4-dihydroxybenzylidene)-2-methylthiosemicarbazide

Scheme 1 Chemical structure of thiosemicarbazide derivative

\section{Preparation of the electrode}

For the preparation of DBT-CNT composite solution, $10 \mathrm{mg}$ of DBT and $10 \mathrm{mg}$ of CNTs were added into the $7.5 \mathrm{~mL}$ of dimethyl formamide (DMF). This mixture was dispersed for $30 \mathrm{~min}$, stirred for $48 \mathrm{~h}$ at room temperature, and centrifuged for $10 \mathrm{~min}$ at $500 \mathrm{rpms}$, respectively. This sample was first washed off with DMF to ensure removal of unadsorption DBT from CNT surface and then dried at $50{ }^{\circ} \mathrm{C}$ under vacuum for $14 \mathrm{~h}$ to obtain the DBT-CNT composites. One milligram of obtained composite was added into $0.5 \mathrm{~mL}$ ethanol, dispersed for $30 \mathrm{~min}$. In order to prepare DBT-CNT/GCmodified electrode, we dropped $4 \mu \mathrm{L}$ of dispersed DBTCNT solution composite on the surface of GC electrode and dried it at the ambient laboratory temperature.

\section{Results and discussion} Characterization of DBT-CNT

Scanning electron microscopy was used to detect possible morphological changes on CNTs after the acid treatment. SEM images of CNTs before and after oxidation are shown in Fig. 1. The raw CNT before oxidation being strongly entangled, it is practically impossible to align them (Fig. 1a). As the oxidation proceeds, the CNTs are gradually freed from the entanglements favoring their alignment. The stronger oxidation reagent, for example, acids, will induce more carboxyl groups than hydroxyl groups on the CNTs.

\section{Electrochemical properties of DBT-CNT/GCE}

The electrochemical behavior of the DBT-CNT/GC modified electrode was investigated by cyclic voltammetry at different scan rates in a buffered solution $(\mathrm{pH}=$ 7.0). The $\mathrm{pH}$ effect on the modified electrode signal was examined by $\mathrm{CV}$ using $0.1 \mathrm{M}$ phosphate buffer solutions at different $\mathrm{pH}$ values. We selected $\mathrm{pH} 7$ for the study because $\mathrm{pH}=7$ showed maximum electrocatalyst behavior. Also, $\mathrm{pH}=7$ is the $\mathrm{pH}$ of biological environment. A potential-pH diagram showed a straight line with a slope, nearly $60 \mathrm{mV} / \mathrm{pH}$. Such behavior suggests a twoelectron, two-proton process. Insolubility of DBT in an aqueous media is its advantage as electrode modifier. It ensures lack of leaching DBT from the CNT surface.

In Fig. 2, the CVs were obtained for the DBT-CNT/ GCE in the absence of IP. The cyclic voltammograms in Fig. 2a indicated that the electrode process was quasireversible, because $\Delta E_{\mathrm{p}}$ was higher than $(59 / \mathrm{n}) \mathrm{mV}$ the same as a reversible system. In Fig. $2 b$, both the anodic and cathodic peak currents $\left(I_{\mathrm{p}}\right)$ increased linearly with the scan rate. In addition, they were linearly dependent on $v$ in the range of 10 to $1800 \mathrm{mVs}^{-1}$, indicating that redox process is controlled in a diffusion-independent manner for a surface-confined redox process. 


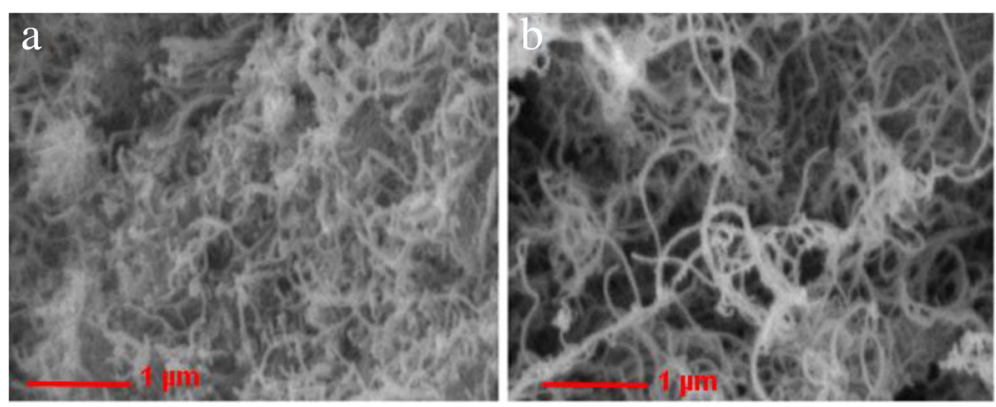

Fig. 1 SEM images of MWCNTs before oxidation (a) and after oxidation (b)

For the purpose of estimating electron transfer rate constant $\left(\mathrm{k}_{\mathrm{s}}\right)$ and the transfer coefficient $(\alpha)$ of DBT, we used $\mathrm{CV}$ voltamograms in condition that the variations of anodic and cathodic peak potentials with logarithm of scan rate were studied by Laviron procedure (Laviron 1979). Figure 2c shows the variations of peak potentials $\left(E_{\mathrm{p}}\right)$ as a function of the logarithm of the potential scan rate. At high scan rates (above $100 \mathrm{mVs}^{-1}$ ), these plots become linear. The slopes of these linear segments in Fig. $2 \mathrm{~d}$ can be applied to estimate the kinetic parameters. The slope of the linear segments is equal to $-2.303 R T /$ $\alpha n_{\alpha} F$ for the cathodic peak and 2.303RT/(1- $\left.\alpha\right) n_{\alpha} F$ for anodic peak $\left(n_{\alpha}\right.$ is the number of electron in rate determining step). The values of anodic and cathodic transfer coefficients were obtained as $\alpha_{\mathrm{a}}=0.47$ and $\alpha_{\mathrm{c}}=$ 0.53. Furthermore, Eq. (1) was used to obtain $\mathrm{k}_{\mathrm{s}}$ between DBT and CNT/GCE:

$$
\begin{aligned}
\log \mathrm{k}_{\mathrm{s}}=\alpha \log (1-\alpha) & +(1-\alpha) \log \alpha-\log (\mathrm{RT} / n F v) \\
& -\alpha(1-\alpha) n_{\alpha} F \Delta \mathrm{E}_{\mathrm{p}} / 2.3 \mathrm{RT}
\end{aligned}
$$

In Eq. (1), $v$ is the sweep rate and $n$ is the number of electrons involved in the overall redox reaction of the modifier (DBT), and all other symbols have their ordinary meanings. The amount of $k_{\mathrm{s}}$ was obtained to be $0.512 \mathrm{~s}^{-1}$.
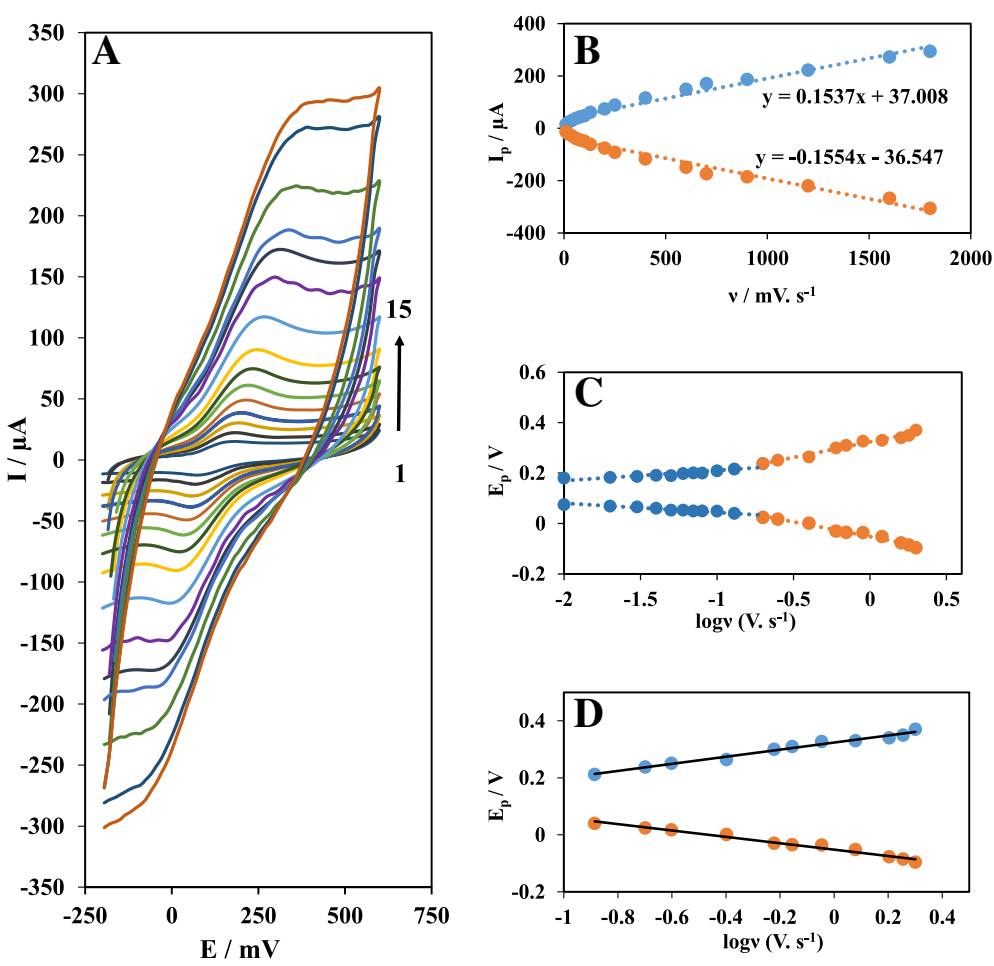

Fig. 2 a CVs of DBT-CNT/GCE in phosphate buffer (pH 7.0, 0.1 M) at scan rates of 10 (1), 20 (2), 40 (3), 60 (4), 100 (5), 130 (6), 200 (7), 250 (8), 400 (9), 600 (10), 700 (11), 900 (12), 1200 (13), 1600 (14), and 1800 (15) $\mathrm{mVs}^{-1}$. b Variations in /p with scan rate. c Variations in $E_{\mathrm{p}}$ with logarithm of scan rate. $\mathbf{d}$ Magnification of the same plots for high scan rates 
An approximate estimate of the surface coverage of the electrode $\left(\Gamma / \mathrm{mol} \mathrm{cm}^{-2}\right)$ was obtained by the method used by Sharp et al (Sharp et al. 1979). According to this method, the peak current is related to the surface concentration of electroactive species by the following Eq. (2):

$$
I_{\mathrm{p}}=n^{2} F^{2} A \Gamma v / 4 \mathrm{RT}
$$

Where $I_{\mathrm{p}}$ represents the current peak, $A$ is the surface of electrode $\left(\mathrm{cm}^{2}\right)$, and $\Gamma$ is the surface coverage $(\mathrm{mol} /$ $\left.\mathrm{cm}^{2}\right)$, and there is no relationship between $\Gamma\left(\mathrm{mol} / \mathrm{cm}^{2}\right)$ and geometric surface area. The other symbols have their usual meanings. $\Gamma=1.30 \times 10^{-6} \mathrm{~mol} / \mathrm{cm}^{2}$ for $n=2$ was calculated from the slope of the anodic peak current versus scan rate (Fig. 2b).

\section{Electrocatalytic oxidation of IP at DBT-CNT/GCE}

The cyclic voltammetric responses from the electrochemical oxidation of $2 \mathrm{mM}$ IP at the DBT-CNT/GCE are shown in Fig. 3. The comparison of $\mathrm{CV}$ at $\mathrm{GCE}$ (Fig. 3 (curve c)) and DBT-CNT/GCE (Fig. 3 (curve d)) exhibited an increase of the anodic peak current at DBT-CNT/GCE, which indicated that the presence of DBT-CNT on the GCE could improve the peak currents. Also, the results showed that the peak potential of

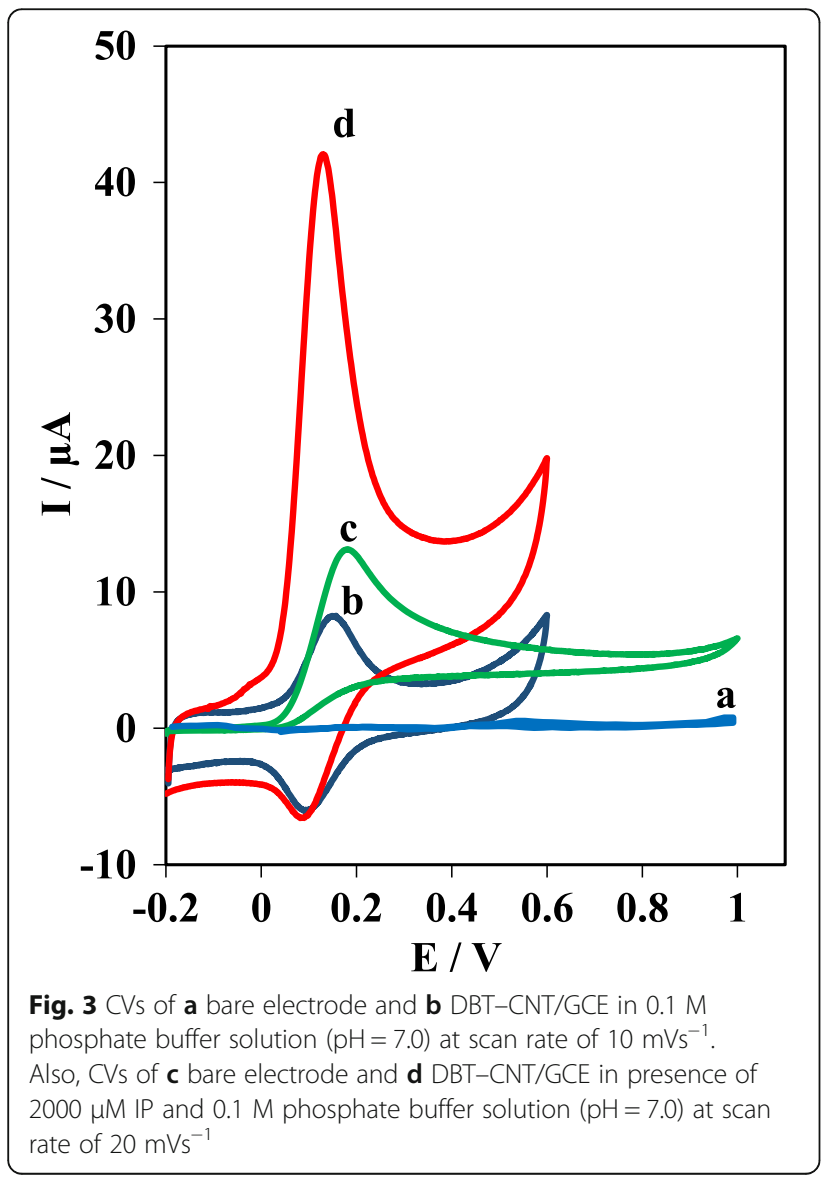

IP oxidation at the bare GCE (Fig. 3 (curve c)) and DBT-CNT/GCE (Fig. 3 (curve d)) was about 190 and $138 \mathrm{mV}$, respectively. These curves (curves $\mathrm{c}$ and $\mathrm{d}$ of Fig. 3) indicated the peak potential of IP oxidation at the surface of modified electrode shifts up to $52 \mathrm{mV}$ toward negative values in comparison to that at the bare electrode. It is worth mentioning that the measurement of $\mathrm{CV}$ for both bare and modified electrodes in the presence of IP shows an increase of anodic current remarkably, whereas current is lower in the absence of IP. From these results, it was concluded that the best electrocatalytic effect for IP oxidation was observed at the DBT-CNT/GCE.

Figure 4a shows effect of scan rate on the electrocatalytic oxidation of IP at the DBT-CNT/GCE by cyclic voltammetry, the oxidation peak potential moved with increasing scan rates to a more positive potential, confirming the kinetic limitation of the electrochemical reaction. We can expect very clear cathodic peak at higher scan rate (Bard and Faulkner 2001). A linear plot of peak current $\left(I_{\mathrm{p}}\right)$ vs the square root of the scan rate $\left(v^{1 / 2}\right)$ was depicted (Fig. 4b). It expresses that the process is diffusion controlled. So, a plot of the scan ratenormalized current $\left(I_{\mathrm{p}} / v^{1 / 2}\right)$ against scan rate (Fig. $4 \mathrm{c}$ ) indicates that the characteristic shape typical of an EC' process. Figure $4 \mathrm{~d}$ exhibits the Tafel plot, drawn by using the data extracted from the increasing segment of the current-voltage curve at a scan rate of $10 \mathrm{mVs}^{-1}$. Charge transfer coefficient $\alpha=0.42$ was estimated from slope of the Tafel plot. The redox reaction scheme of DBT has been shown in Scheme 2.

\section{Chronoamperometric measurements}

In the chronoamperometric studies, we calculated the diffusion coefficient of IP at the DBT-CNT/GCE based on the Cottrell equation (Bard and Faulkner 2001). Chronoamperograms of IP at DBT-CNT/GCE were showed at different concentrations of IP (Fig. 5). At first, plots of $I$ against $t^{-1 / 2}$ were depicted with the best fits for different concentrations of IP (Fig. 5 (A)). Then, the slopes of the obtained straight lines were plotted versus IP concentrations (Fig. 5 (B)). Finally, from the resulting slope and Cottrell equation, the value of the diffusion coefficient was estimated $\left(D=1.56 \times 10^{-5} \mathrm{~cm}^{2} \mathrm{~s}^{-1}\right)$.

\section{Calibration curve and limit of detection for IP}

In view of high sensitivity, differential pulse voltammetry (DPV) was used to acquire the calibration curve and detection limit of IP at the DBT-CNT/GCE (Fig. 6). The plot of peak current vs IP concentration included two linear segments with different slopes and different concentration ranges of $0.5-100.0 \mu \mathrm{M}$ and $100.0-1500.0 \mu \mathrm{M}$, respectively (inset of Fig. 6). The slope in high concentrations of IP (range of $100.0-1500.0 \mu \mathrm{M}$ ) is lower. It reduces, probably 

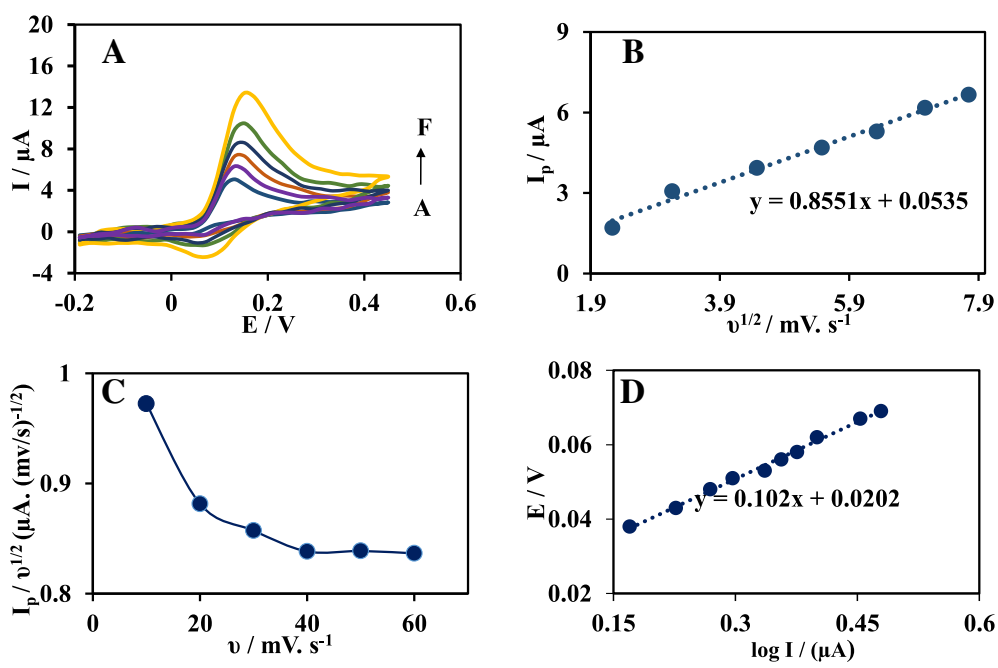

Fig. 4 a Cyclic voltammograms of DBT-CNT/GCE in a $0.1 \mathrm{M}$ phosphate buffer ( $\mathrm{pH}=7.0$ ) containing $1000 \mu \mathrm{M}$ IP at different scan rates, CVs A-F corresponding to $10,15,20,25,30$, and $40 \mathrm{mVs}^{-1}$ scan rates. $\mathbf{b}$ Variation of the electrocatalytic currents versus the square root of the scan rate. c Variation of the scan rate-normalized current $\left(I_{\mathrm{p}} / \mathrm{U}^{1 / 2}\right)$ with scan rate. $\mathbf{d}$ Tafel plot derived from the rising part of the voltammogram recorded at a scan rate of $10 \mathrm{mVs}^{-1}$

due to two reasons. The first reason is kinetic limitations (Mazloum-Ardakani and Khoshroo 2013; Taleat et al. 2008; Zare et al. 2006). The second is the presence of lower empty sites in surface of electrode in range of 100.0$1500.0 \mu \mathrm{M}$ in comparison with lower range.

The detection limit $(3 \sigma)$ was computed from the first linear segment of the calibration plot as $0.35 \mu \mathrm{M}$.

\section{Simultaneous determination of isoprenaline and piroxicam}

In this study, DPV was applied to detect IP and PX (piroxicam) simultaneously. The results represented two

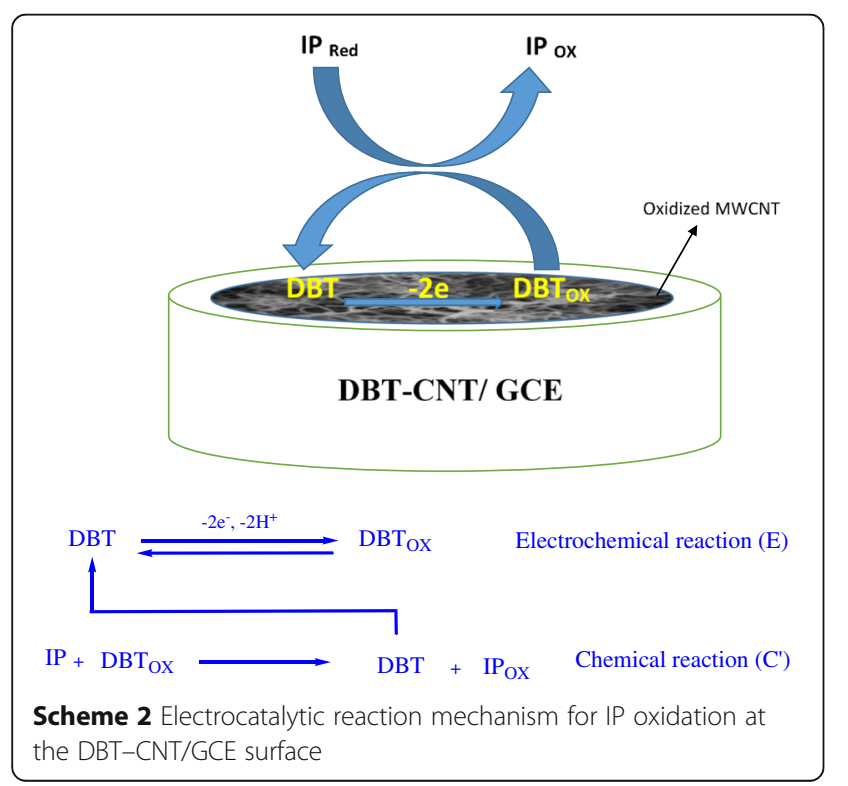

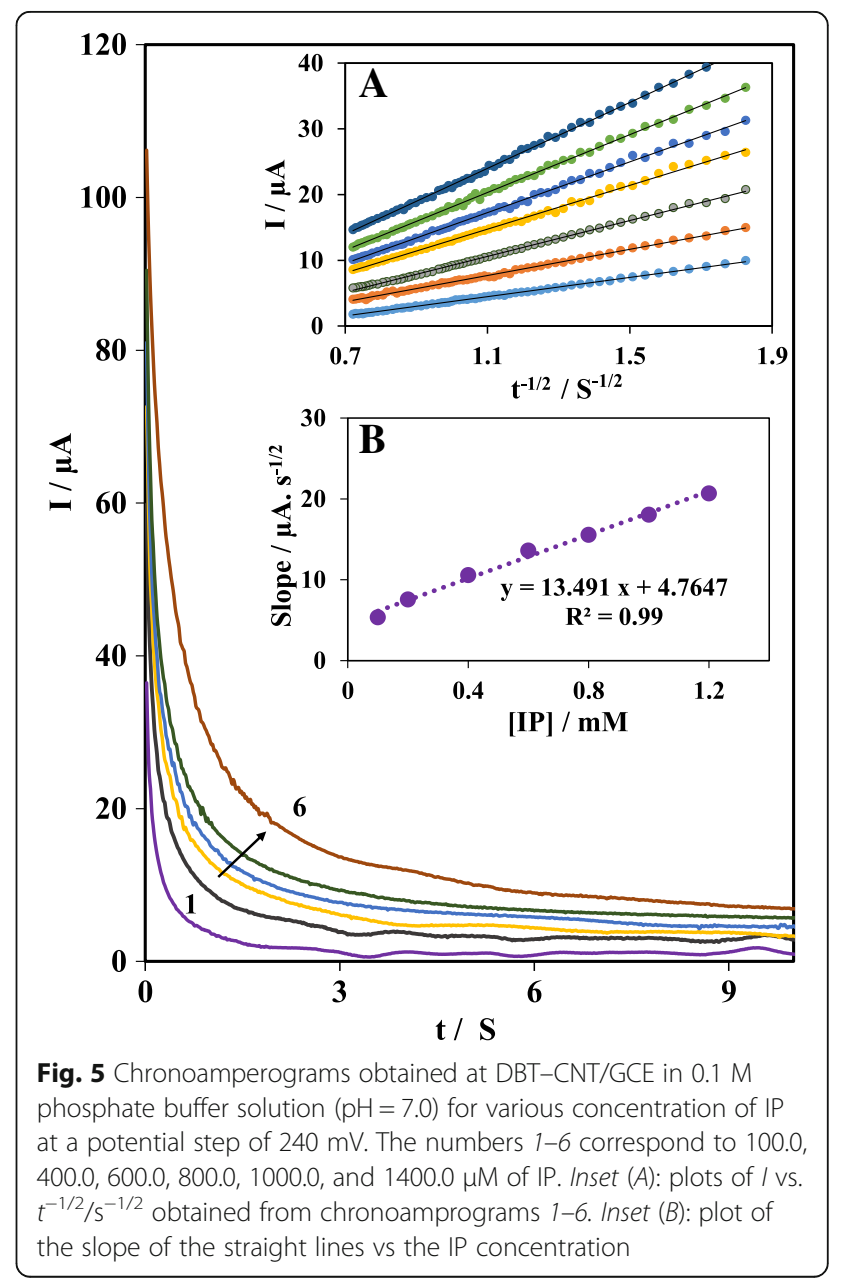




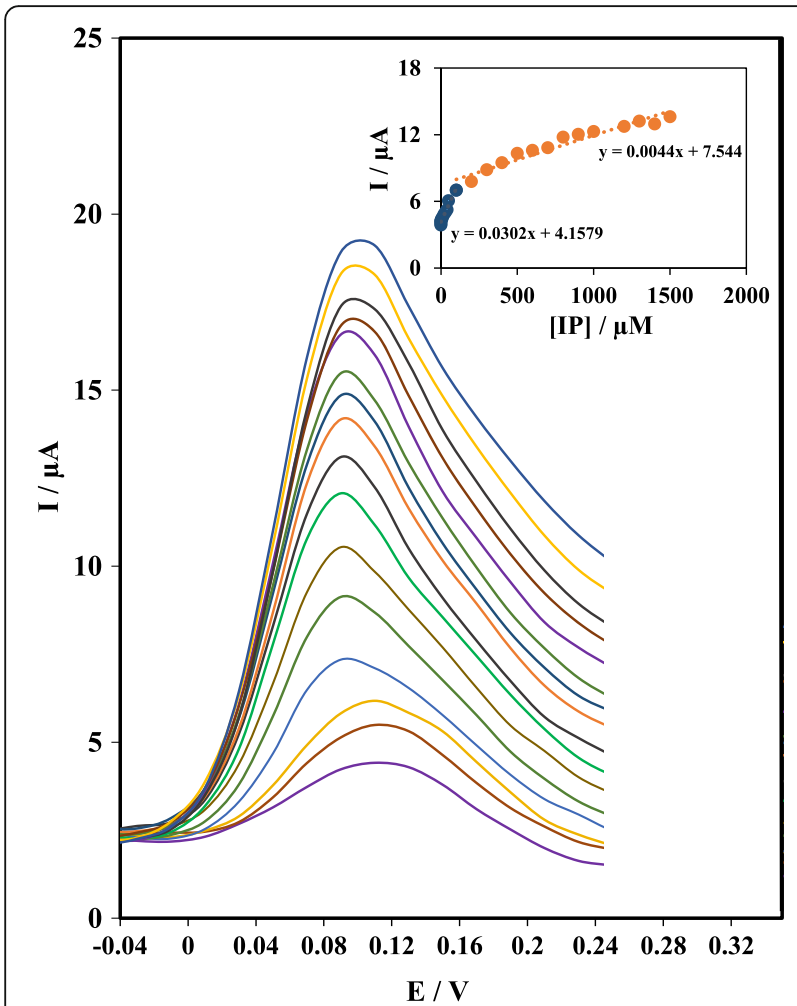

Fig. 6 DPVs of DBT-CNT/GCE in $0.1 \mathrm{M}$ buffer solution ( $\mathrm{pH}=7.0$ ) containing different concentrations of IP (inner to outer corresponds to $50.0,100.0,200.0,300.0,400.0,500.0,600.0,700.0,800.0,1000.0$, 1200.0, and $1300.0 \mu \mathrm{M})$. Inset: calibration plot of IP well-separated anodic peaks for the oxidation of IP and PX at potentials of 100 and $400 \mathrm{mV}$ at the surface of the DBT-CNT/GCE (Fig. 7a). The sensitivity of the modified electrode to the oxidation of IP was obtained $\left(0.0044 \mu \mathrm{A} \mu \mathrm{M}^{-1}\right)$. Moreover, the sensitivity of IP in the presence of PX was obtained $\left(0.0067 \mu \mathrm{A} \mu \mathrm{M}^{-1}\right)$. The sensitivities of the modified electrode for IP in the presence and absence of PX were the same approximately; this suggested that the oxidation processes of IP and PX at modified electrode were independent. Consequently, independent measurements of the two analytes are reasonable without any interference. If slopes were different, PX would affect the IP signal.

\section{Interference study}

The influence of different species on the determination of $1 \mathrm{mM}$ IP was investigated. When the relative error was less than $\pm 5 \%$, no interference was realized in the presence of $1 \mathrm{mM}$ of $\mathrm{K}^{+}, \mathrm{Na}^{+}, \mathrm{NH}_{4}^{+}, \mathrm{Cl}^{-}, \mathrm{F}^{-}, \mathrm{Br}^{-}$, glucose, fructose, uric acid, and caffeine. In addition, no interference was realized in the presence of $0.5 \mathrm{mM}$ of L-alanine, ascorbic acid, and L-cysteine.

\section{Determination of IP and PX in human blood serum samples}

The explained method was examined by direct analysis of IP and PX in blood serum samples as real samples. For preparation of real sample, $1 \mathrm{~mL}$ blood serum is diluted in $20 \mathrm{~mL}$ buffer solution and placed in the electrochemical
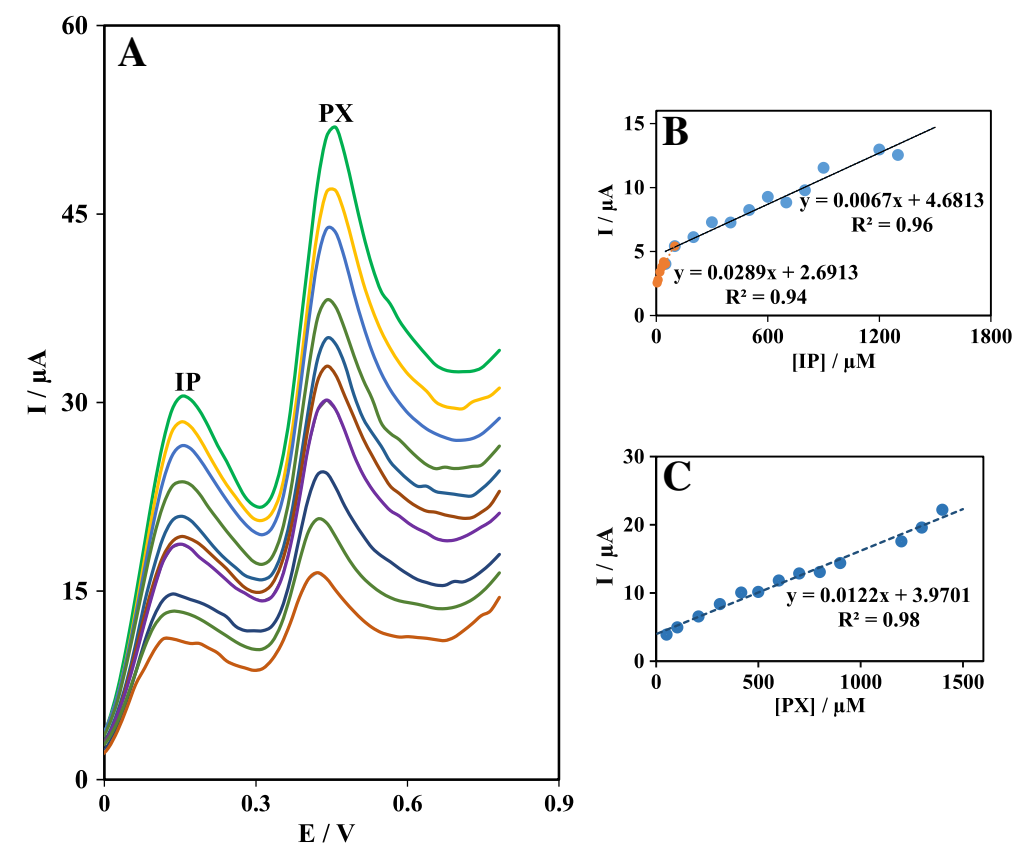

Fig. 7 (a) DPVs of DBT-CNT/GCE in buffer solution ( $\mathrm{pH}=7.0$ ) containing different concentrations of IP and PX: from inner to outer corresponds to mixed solutions of $100.0+104.1,300.0+312.3,400.0+416.9,500.0+500.3,700.0+700.4,800.0+800.5,900.0+900.6,1000.0+999.7,1200.0+1199.5$, and 1300.0 +1299.8, (b) Calibration plot of IP and (c) Calibration plot of PX 
Table 1 Recovery for different amounts of IP and PX spiked to the blood serum

\begin{tabular}{lccl}
\hline Sample & Added $(\mu \mathrm{M})$ & Found $(\mu \mathrm{M})$ & Recovery $(\%)$ \\
\hline IP & 300.0 & 286.8 & 95.6 \\
& 400.0 & 412.8 & 103.2 \\
& 600.0 & 585.36 & 97.56 \\
PX & 200.0 & 201.4 & 100.7 \\
& 400.0 & 404.4 & 101.1 \\
& 600.0 & 593.94 & 98.99 \\
\hline
\end{tabular}

cell. Known amount of IP and PX were spiked in real samples. Each solution was analyzed by DPV. Based on the currents of DPVs and using the calibration plots, the concentration and recovery of IP and PX are calculated. The results are shown in Table 1 . The obtained results and recoveries exhibited that the DBT-CNT/GCE showed great catalytic activity for serum samples which contained diverse biological and mineral compounds.

\section{The repeatability and stability of DBT-CNT/GC electrode}

The repeatability of electrode surface was investigated by use of cyclic voltammetry for several separately prepared DBT-CNT/GCEs. The obtained RSD demonstrated that surface repeatability was acceptable with the amount of RSD $=4.0 \%$. Also, reproducibility study was examined. For this purpose, we investigated cyclic voltammograms of modified electrode in different days. The results showed $\mathrm{RSD}=4.8 \%$. Besides, the stability of the DBT-CNT/GCEs was studied by recording CVs of IP after having cycled the potential 25 times at a scan rate of $10 \mathrm{mVs}^{-1}$. The peak potentials were invariant, and the currents decreased by less than $2.13 \%$.

To examine the antifouling property, it was recorded two cyclic voltammograms in solution of buffer $(\mathrm{pH}=7.0)$ and IP at a scan rate of $10 \mathrm{mVs}^{-1}$. The first was recorded as soon as putting the modified electrode in solution, and the second was recorded after passing $1 \mathrm{~h}$ from staying electrode in the solution. The results showed that peak potentials remained unchanged, and the currents reduced by less than $4.1 \%$.

\section{Conclusions}

Chemically functionalized carbon nanotubes have presented a significant role in the investigation and progression of nanotube-based materials and systems. Improvement of dispersion and solubility of the carbon nanotubes associated with the functionalization and chemical modification exhibit great opportunities in the fabrication and the employment of carbon nanotubes for various nanostructures. In this paper, a simple preparation technique has been explained for fabrication of functionalized nanotube-based electrode to detect different concentrations of IP and PX simultaneously. The electrochemical behavior of the modified electrode was examined by $\mathrm{CV}$, and it was realized that the utilization of potential cycling ensures great electrochemical reproducibility and mechanical stability of the deposited electrocatalyst. The oxidation of IP is catalyzed in a buffered aqueous solution $(\mathrm{pH}=7.0)$ at DBT-CNT/GCE. It was proved with shifted peak potential of IP to a less positive potential rather than bare GCE. This proposed sensor has been successfully applied to determine the IP and PX in blood serum human, which demonstrates that it has excellent potential application for detection of different concentrations of IP and PX.

\section{Abbreviations \\ CNTs: Carbon nanotubes; CV: Cyclic voltammetry; DBT: (z)-1-(3,4- \\ dihydroxybenzylidene)-2-methylthiosemicarbazide; DMF: Dimethylformamide; DPV: Differential pulse voltammetry; FTIR: Fourier transform infrared spectroscopy; GCE: Glassy carbon electrode; IP: Isoprenaline; MWNT: Multiwalled carbon nanotubes; NMR: Nuclear magnetic resonance spectroscopy; NSAID: Nonsteroidal anti-inflammatory drug; PX: Piroxicam; rpm: Revolutions per minute; RSD: Relative standard deviation; \\ SEM: Scanning electron microscope; SWNT: Single-walled carbon nanotubes}

\section{Acknowledgements}

The authors wish to thank the Yazd University Research Council, IUT Research Council and Excellence in Sensors for financial support of this research.

\section{Authors'contributions}

MMA and AK designed the experiment and drafted the manuscript. Experimental part and calculations were carried out by HMS. Synthesis of DBT and obtaining information of NMR and FTR were performed by MAA. The corresponding author is MMA. All the authors have read and approved the final manuscript.

\section{Competing interests}

The authors declare that they have no competing interests.

\section{Publisher's Note}

Springer Nature remains neutral with regard to jurisdictional claims in published maps and institutional affiliations.

Received: 30 September 2016 Accepted: 9 March 2017 Published online: 12 April 2017

\section{References}

Andrews R, Weisenberger MC. Carbon nanotube polymer composites. Curr Opin Solid State Mater Sci. 2004:8(1):31-7.

Bahr JL, Tour JM. Highly functionalized carbon nanotubes using in situ generated diazonium compounds. Chem Mater. 2001;13(11):3823-4.

Balasubramanian K, Burghard M. Chemically functionalized carbon nanotubes. Small. 2005;1 (2):180-92.

Bard AJ, Faulkner LR. Electrochemical methods: fundamentals and applications. 2nd ed. New York: Wiley; 2001.

Beitollahi H, Karimi-Maleh H, Khabazzadeh H. Nanomolar and selective determination of epinephrine in the presence of norepinephrine using carbon paste electrode modified with carbon nanotubes and novel 2-(4-oxo3-phenyl-3, 4-dihydro-quinazolinyl)-N'-phenyl-hydrazinecarbothioamide. Anal Chem. 2008;80(24):9848-51.

Benvidi A, Kakoolaki P, Zare HR, Vafazadeh R. Electrocatalytic oxidation of hydrazine at a Co (II) complex multi-wall carbon nanotube modified carbon paste electrode. Electrochim Acta. 2011;56(5):2045-50. 
Chen J, Rao AM, Lyuksyutov S, Itkis ME, Hamon MA, Hu H, et al. Dissolution of full-length single-walled carbon nanotubes. J Phys Chem B. 2001a;105(13): 2525-8.

Chen RJ, Zhang Y, Wang D, Dai H. Noncovalent sidewall functionalization of single-walled carbon nanotubes for protein immobilization. J Am Chem Soc. 2001b;123(16):3838-9.

Fernando KAS, Lin Y, Wang W, Kumar S, Zhou B, Xie S-Y, et al. Diminished bandgap transitions of single-walled carbon nanotubes in complexation with aromatic molecules. J Am Chem Soc. 2004;126(33):10234-5.

Georgakilas V, Kordatos K, Prato M, Guldi DM, Holzinger M, Hirsch A. Organic functionalization of carbon nanotubes. J Am Chem Soc. 2002;124(5):760-1.

Holzinger M, Vostrowsky O, Hirsch A, Hennrich F, Kappes M, Weiss R. Sidewall functionalization of carbon nanotubes. Angew Chem Int Ed. 2001;40(21): 4002-5.

Huang W, Fernando S, Allard LF, Sun Y-P. Solubilization of single-walled carbon nanotubes with diamine-terminated oligomeric poly (ethylene glycol) in different functionalization reactions. Nano Lett. 2003;3(4):565-8.

Jin G-P, Lin X-Q. The electrochemical behavior and amperometric determination of tyrosine and tryptophan at a glassy carbon electrode modified with butyrylcholine. Electrochemistry Commun. 2004;6(5):454-60.

Jin Z, Sun X, Xu G, Goh SH, Ji W. Nonlinear optical properties of some polymer/multi-walled carbon nanotube composites. Chem Phys Lett. 2000:318(6):505-10

Kate VK, Payghan SA, Shinde AJ. Effect of aging conditions on the dissolution stability of piroxicam mucoadhesive fast disintegrating tablet. Inventi Rapid: NDDS. 2013;2013(2):1-6.

Laviron E. General expression of the linear potential sweep voltammogram in the case of diffusionless electrochemical systems. J Electroanalytical Chem Interfacial Electrochemistry. 1979;101(1):19-28.

Lee SH, Cho E, Jeon SH, Youn JR. Rheological and electrical properties of polypropylene composites containing functionalized multi-walled carbon nanotubes and compatibilizers. Carbon. 2007:45(14):2810-22.

Lin Y, Rao AM, Sadanadan B, Kenik EA, Sun Y-P. Functionalizing multiple-walled carbon nanotubes with aminopolymers. J Phys Chem B. 2002;106(6):1294-8.

Mandell GL, Petri WA. Goodman and Gilman's the pharmacological basis of therapeutics. New York: McGraw-Hill; 1996. p. 1073-101.

Mazloum-Ardakani M, Abolhasani M, Mirjalili B-F, Sheikh-Mohseni MA, DehghaniFirouzabadi A, Khoshroo A. Electrocatalysis of dopamine in the presence of uric acid and folic acid on modified carbon nanotube paste electrode. Chin J Catalysis. 2014:35(2):201-9. Available from: http://www.sciencedirect.com/ science/article/pii/S1872206712607347.

Mazloum-Ardakani M, Beitollahi H, Ganjipour B, Naeimi H, Nejati M. Electrochemical and catalytic investigations of dopamine and uric acid by modified carbon nanotube paste electrode. Bioelectrochemistry. 2009;75(1):1-8

Mazloum-Ardakani M, Beitollahi H, Mohseni MAS, Benvidi A, Naeimi H, NejatiBarzoki $\mathrm{M}$, et al. Simultaneous determination of epinephrine and acetaminophen concentrations using a novel carbon paste electrode prepared with 2,2'-[1,2 butanediylbis(nitriloethylidyne)]-bis-hydroquinone and TiO2 nanoparticles. Colloids Surfaces B: Biointerfaces. 2010;76(1):82-7.

Mazloum-Ardakani M, Khoshroo A. An electrochemical study of benzofuran derivative in modified electrode-based CNT/ionic liquids for determining nanomolar concentrations of hydrazine. Electrochim Acta. 2013;103:77-84.

Mazloum-Ardakani M, Naser-Sadrabadi A, Sheikh-Mohseni MA, Naeimi H, Benvidi A, Khoshroo A. Oxidized multiwalled carbon nanotubes for improving the electrocatalytic activity of a Schiff base modified electrode in determination of isoprenaline. J Electroanalytical Chem. 2013;705:75-80. Available from: http://dx.doi.org/10.1016/j.jelechem.2013.07.028.

Murray RW. Chemically modified electrodes. Electroanalytical Chem. 1984; 13:191-368.

Reddy KR, Sin BC, Ryu KS, Kim J-C, Chung H, Lee Y. Conducting polymer functionalized multi-walled carbon nanotubes with noble metal nanoparticles: synthesis, morphological characteristics and electrical properties. Synth Met. 2009;159(7):595-603.

Riggs JE, Walker DB, Carroll DL, Sun Y-P. Optical limiting properties of suspended and solubilized carbon nanotubes §. J Phys Chem B. 2000; 104(30):7071-6.

Santana MHP, Da Silva LM, Freitas AC, Boodts JFC, Fernandes KC, De Faria LA. Application of electrochemically generated ozone to the discoloration and degradation of solutions containing the dye Reactive Orange 122. J Hazardous Mater. 2009;164(1):10-7.
Sharp M, Petersson M, Edström K. Preliminary determinations of electron transfer kinetics involving ferrocene covalently attached to a platinum surface. J Electroanalytical Chem Interfacial Electrochemistry. 1979;95(1):123-30.

Stryer L. Biochemie. Heidelberg: Spektrum der Wissenschaft, 1990.

Sun Y-P, Fu K, Lin Y, Huang W. Functionalized carbon nanotubes: properties and applications. Acc Chem Res. 2002;35(12):1096-104.

Sun Y-P, Huang W, Lin Y, Fu K, Kitaygorodskiy A, Riddle LA, et al. Soluble dendron-functionalized carbon nanotubes: preparation, characterization, and properties §,\|. Chem Mater. 2001;13(9):2864-9.

Taleat Z, Mazloum Ardakani M, Naeimi H, Beitollahi H, Nejati M, Reza Zare H. Electrochemical Behavior of Ascorbic Acid at a 2, 2'-[3, 6-Dioxa-1, 8octanediylbis (nitriloethylidyne)]-bis-hydroquinone Carbon Paste Electrode. Anal Sci. 2008;24(8):1039-44.

Tasis D, Tagmatarchis N, Bianco A, Prato M. Chemistry of carbon nanotubes. Chem Rev. 2006;106(3):1105-36.

Tournus F, Latil S, Heggie MI, Charlier J-C. $\pi$-stacking interaction between carbon nanotubes and organic molecules. Phys Rev B. 2005;72(7):75431.

Wang Y, Wu J, Wei F. A treatment method to give separated multi-walled carbon nanotubes with high purity, high crystallization and a large aspect ratio. Carbon. 2003:41(15):2939-48.

Zare HR, Nasirizadeh N, Golabi S-M, Namazian M, Mazloum-Ardakani M, Nematollahi D. Electrochemical evaluation of coumestan modified carbon paste electrode: study on its application as a NADH biosensor in presence of uric acid. Sensors Actuators B Chem. 2006;114(2):610-7.

Zhu J-T, Shi C-G, Xu J-J, Chen H-Y. Direct electrochemistry and electrocatalysis of hemoglobin on undoped nanocrystalline diamond modified glassy carbon electrode. Bioelectrochem. 2007;71(2):243-8.

\section{Submit your manuscript to a SpringerOpen ${ }^{\circ}$ journal and benefit from:}

- Convenient online submission

- Rigorous peer review

- Immediate publication on acceptance

- Open access: articles freely available online

- High visibility within the field

- Retaining the copyright to your article

Submit your next manuscript at $>$ springeropen.com 